\title{
N-Mating in Escherichia coli is Promoted by Foaming
}

\author{
By PAUL SINGLETON \\ Hatherly Laboratories, Department of Biological Sciences, University of Exeter, \\ Exeter EX4 4PS, U.K.
}

(Received 7 June 1983; revised 11 July 1983)

Foaming promoted the conjugal transfer of IncN plasmid R269N-1 in Escherichia coli; the theoretical basis of this phenomenon is described. The hypothesis that $\mathbf{N}$-mating in conventional (non-foaming) liquid media is precluded by the fragility of the $\mathbf{N}$-pilus is questioned. The environmental significance of foaming is briefly considered.

\section{INTRODUCTION}

It is generally accepted that the conjugal transfer of IncN plasmids ( $\mathrm{N}$-mating) occurs efficiently only on the surface of solid media (Dennison \& Baumberg, 1975; Bradley et al., 1980; Bradley, 1981; Rodriguez \& Iyer, 1981; Gill \& Iyer, 1982), and this has been attributed to the fragility of $\mathrm{N}$-pili in liquid media (Bradley et al., 1980; Bradley, 1981). However, it was recently shown that the apparent requirement for solid media can be explained in terms of surface tension (Singleton, 1983). From this finding it may be predicted that $\mathrm{N}$-mating should occur in a foaming liquid since surface energy is available, e.g. within the lamellae of the foam (Davies \& Rideal, 1961); moreover, bacteria are known to be concentrated in surface films and bubbles (Bezdek \& Carlucci, 1972) - thus increasing the potential for cell-cell contact. This paper confirms that foaming does indeed promote $\mathrm{N}$-mating.

\section{METHODS}

Parent cultures were prepared according to Dennison \& Baumberg (1975) using as donor Escherichia coli J53 containing R269N-1, and as recipient a strain of $E$. coli J53 which was chromosomally resistant to nalidixic acid. Mating mixtures, each $6 \mathrm{ml}$, were prepared from equal volumes of donor and recipient parent cultures and incubated for $30 \mathrm{~min}$ at $37^{\circ} \mathrm{C}$. Control matings were not shaken; experimental matings were shaken vigorously by hand for $10 \mathrm{~s}$ at 5 -min intervals to generate foam. After $30 \mathrm{~min}$ incubation $0.05 \mathrm{ml}$ aliquots of each mating mixture were plated for transconjugants on agar containing nalidixic acid, ampicillin and kanamycin, and incubated overnight at $37^{\circ} \mathrm{C}$. [N-mating can occur on plates containing antibiotics (Dennison \& Baumberg, 1975; Gill \& Iyer, 1982; Singleton, 1983); such plates therefore permit the growth of transconjugants formed on the plate as well as those, if any, present in the inoculum.] The experiment was carried out four times to check reproducibility.

\section{RESULTS AND DISCUSSION}

Plates inoculated from the foaming media invariably yielded approximately twice the number of transconjugant colonies (mean $2 \cdot 3 \times$ ) compared with plates inoculated from control matings; mean transfer frequencies were $9 \times 10^{-6}$ in control matings, and $2.1 \times 10^{-5}$ in experimental matings. Previous work with R269N-1 (Dennison \& Baumberg, 1975), confirmed in this laboratory, has shown that transfer of this plasmid in conventional (non-foaming) liquid media is negligible, since similar yields of transconjugants are obtained when mating mixtures are plated with and without an initial period of incubation in liquid media; in other words, mating occurs only after the mating mixture has been spread on to the surface of a plate. [This apparent requirement for solid surfaces is a feature of conjugal transfer mediated by those plasmids which 
specify rigid pili - e.g. IncM, IncN, IncP and IncW plasmids (Bradley et al., 1980).] Thus, in the present work, transfer recorded for the conventional (non-foaming) control matings is attributable to mating which occurred subsequent to plating. Since transfer frequencies recorded from the foaming media were consistently higher than those from controls, and since plating and all subsequent steps were identical in control and experimental matings, it follows that transfer in the experimental matings must have occurred not only on the plates (as in control matings) but also in the foaming liquid media, i.e. transfer frequency in the foaming liquid media was $1.2 \times 10^{-5}$ compared with about zero in non-foaming media.

The increased transfer frequency recorded from the foaming media was not due to increased aeration of the (vigorously shaken) mating mixtures since the transfer frequency of this plasmid is similar under aerobic and anaerobic conditions (Singleton, 1983). Moreover, shaking per se is unlikely to have stimulated conjugal cell-cell contact since high shear forces are known to disrupt, rather than promote, cell-cell contact - at least in F-type mating systems (deHaan \& Gross, 1962; Achtman et al., 1978); additionally, any increase in collision rate (due to shaking) is unlikely to have stimulated conjugal transfer since (i) collision rate was not a limiting factor under these conditions (Cullum et al., 1978), and (ii) additional collisions may disrupt any cellcell contact previously established (Collins \& Broda, 1975). Hence, the results of these experiments indicate that foaming per se can promote $\mathrm{N}$-mating, a finding which supports the view that the lack of $\mathrm{N}$-mating in conventional (non-foaming) liquid media is due to the lack of appropriate surface forces (Singleton, 1983).

That $\mathrm{N}$-mating was enhanced despite vigorous shaking indicates that its absence in conventional liquid media cannot be due to fragility of the $\mathrm{N}$-pilus as suggested by Bradley and his coworkers (Bradley et al., 1980; Bradley, 1981). N-pili may or may not be fragile, but these results indicate that $\mathrm{N}$-mating can nevertheless occur in liquid media if appropriate surface forces are available. If $\mathrm{N}$-pili are fragile they must be able to regenerate rapidly to allow mating to occur under the conditions described above.

The promotion of $\mathrm{N}$-mating by foaming may have environmental significance. Foam is a common sight on rivers and estuaries, particularly those polluted with sewage effluents; such foam could provide suitable conditions for the conjugal transfer of IncN plasmids - first, by its increased concentration of bacteria compared with the main body of water (Bezdek \& Carlucci, 1972), and secondly, by providing the surface energy necessary for this type of conjugation. It is possible that foaming may offer the only opportunity for conjugal transfer of IncN plasmids in a wholly aquatic environment; in soil, and on the surfaces of exposed sediments etc., the opportunity for transfer is much greater owing to the forces of surface tension associated with the thin films of surface water (Singleton, 1983).

I gratefully acknowledge the gift of plasmid R269N-1 from Dr S. Baumberg, Department of Genetics, University of Leeds, and I thank Diana Sainsbury for stimulating discussions.

This work was supported by a grant from the Natural Environment Research Council.

\section{REFERENCES}

Achtman, M., Morelli, G. \& Schwuchow, S. (1978). Cell-cell interactions in conjugating Escherichia coli: role of $\mathrm{F}$ pili and fate of mating aggregates. Journal of Bacteriology 135, 1053-1061.

Bezdex, H. F. \& CarlucCi, A. F. (1972). Surface concentration of marine bacteria. Limnology and Oceanography 17, 566-569.

BradLey, D. E. (1981). Conjugative pili of plasmids in Escherichia coli $\mathrm{K}-12$ and Pseudomonas species. In Molecular Biology, Pathogenicity, and Ecology of Bacterial Plasmids, pp. 217-226. Edited by S. B. Levy, R. C. Clowes, and E. L. Koenig. New York: Plenum Press

Bradley, D. E., Taylor, D. E. \& Cohen, D. R. (1980). Specification of surface mating systems among conjugative drug resistance plasmids in
Escherichia coli K-12. Journal of Bacteriology 143, 1466-1470.

Collins, J. F. \& Broda, P. (1975). Motility, diffusion and cell concentration affect pair formation in Escherichia coli. Nature, London 258, 722-723.

Cullum, J. F., Collins, J. F. \& Broda, P. (1978). Factors affecting the kinetics of progeny formation with F'lac in Escherichia coli K12. Plasmid 1, 536544.

Davies, J. T. \& Rideal, E. K. (1961). Disperse systems and adhesion. In Interfacial Phenomena, pp. 395-416. New York: Academic Press

DEHaAN, P. G. \& Gross, J. D. (1962). Transfer delay and chromosome withdrawal during conjugation in Escherichia coli. Genetical Research 3, 251-272.

DenNison, S. \& BAUMBERG, S. (1975). Conjugational 
behaviour of N plasmids in Escherichia coli K12. RODRIGUEz, M. \& IYER, V. N. (1981). Killing of Molecular and General Genetics 138, 323--331.

GILL, S. \& IYER, V. N. (1982). Nalidixic acid inhibits the conjugal transfer of conjugative $\mathbf{N}$ incompatibility group plasmids. Canadian Journal of Microbiology 28, 256-258. Klebsiella pneumoniae mediated by conjugation with bacteria carrying antibiotic-resistance plasmids of the group N. Plasmid 6, 141-147.

Singleton, P. (1983). N-mating: influence of surface tension. FEMS Microbiology Letters 19, 179-182. 